\title{
Multiple Criteria Decision-Making for Developing an International Game Participation Strategy: A Novel Application of the Data Envelopment Analysis (DEA) Two-Stage Efficiency Process
}

\author{
Yi-Chieh Chen ${ }^{1}$, Lin-Huan $\mathrm{Hu}^{1}{ }^{1} *$, Wan Chen $\mathrm{Lu}^{1, *}$, Jei-Zheng $\mathrm{Wu}^{2} \mathbb{D}$ and Jiun-Jen Yang ${ }^{3}$ \\ 1 Department of Athletics, National Taiwan University, Taipei City 10617, Taiwan; yichiehchen@ntu.edu.tw \\ 2 Department of Business Administration, Soochow University, Taipei City 10013, Taiwan; jzwu@scu.edu.tw \\ 3 College of Medicine, National Taiwan University, Taipei City 10617, Taiwan; jjyangsayshi@gmail.com \\ * Correspondence: lhhu@ntu.edu.tw (L.-H.H.); gracelyu@ntu.edu.tw (W.C.L.)
}

Citation: Chen, Y.-C.; Hu, L.-H.; Lu, W.C.; Wu, J.-Z.; Yang, J.-J. Multiple Criteria Decision-Making for Developing an International Game Participation Strategy: A Novel Application of the Data Envelopment Analysis (DEA) Two-Stage Efficiency Process. Mathematics 2021, 9, 1700. https://doi.org/10.3390/math9141700

Received: 7 June 2021

Accepted: 16 July 2021

Published: 20 July 2021

Publisher's Note: MDPI stays neutral with regard to jurisdictional claims in published maps and institutional affiliations.

Copyright: (c) 2021 by the authors. Licensee MDPI, Basel, Switzerland. This article is an open access article distributed under the terms and conditions of the Creative Commons Attribution (CC BY) license (https:/ / creativecommons.org/licenses/by/ $4.0 /)$.

\begin{abstract}
Background: This study aims to develop an efficient future game participation strategy for teenaged athletes based on an analysis of the 2019 International Table Tennis Federation (ITTF) World Tour game expenditure efficiency and prize-winning efficiency. Methods: In this research, Chinese Taipei (TPE) players served as the main research subjects. The input and output categories were determined through a literature analysis. A two-stage efficiency process of data envelopment analysis (DEA) and Boston consulting group (BCG) matrix were applied in this study to facilitate the calculation. Results: Based on a slack variable analysis, local travel expenses are the key elements impacting efficiency. The game recommendation order was based on a BCG matrix. The top seven recommended games were the Japan Open, Czech Open, Australian Open, Bulgarian Open, Austrian Open, China Open, and German Open. Conclusion: The results of this current study provide efficient game participation recommendations for teenaged athletes. Long-term follow-up records of game participation information should be developed to provide teenaged athletes with a precise efficiency analysis.
\end{abstract}

Keywords: data envelopment analysis; slack variable analysis; world tour platinum; world tour regular

\section{Introduction}

1.1. Background

The most renowned competitions in table tennis are the Olympics Games, the World Championships, and the World Cup. For table tennis athletes, winning all three championships to achieve the Grand Slam title represents the highest honor. Qualification to compete in these three games is based on the world rankings of athletes, which are calculated by adding the points athletes receive from the eight best performing games out of the twelve International Table Tennis Federation (ITTF) World Tour games.

The ITTF World Tour was established in 1996 to adapt to the market- and careeroriented environment of professional sports. Major adjustments were made in 2017, and the games were divided into six World Tour platinum games and six World Tour regular games. A total of twelve games are hosted annually, with each game including men's singles, men's doubles, women's singles, women's doubles, and mixed doubles competitions. Member countries can participate and compete for points and prize money. The fifteen players with the most points along with the player from the hosting country who possesses the most points participate in the December ITTF World Tour Finals. The total prize money is 1 million USD and is thus a long-cherished goal of table tennis athletes. However, not all teenaged athletes have sufficient funding to participate in international games. Without corporate sponsorships, many outstanding teenaged athletes cannot continue their careers 
due to limited financial resources. The official webpage of ITTF World Tour reports statistics only records points, prize money, and the ranking of players. A more efficient index is needed to help young athletes decide whether to join the tournament. As a result, our study aims to develop an ITTF World Tour game participation strategy, as such a strategy will benefit athletes with limited resources when choosing games. This strategy will especially benefit teenaged athletes and assist them as they transition into future professional careers.

In our study, we employed a data envelopment analysis (DEA) to assess the relative efficiency of the ITTF World Tour games from the perspective of Chinese Taipei (TPE) players. DEA was first developed in 1957 by Farrell [1] and was subsequently modified by Charnes et al. [2] and Banker et al. [3]. DEA is a linear programming method used to evaluate the relative efficiency between decision-making units (DMUs). It assigns each DMU an efficiency score that is comparable to those of other DMUs. DEA is considered an adequate method for evaluating efficiency across a variety of domains, such as economics [4], country development [5], universities, financial institutions, and others [6]. The use of DEA in analysis of the sports industry has flourished in recent years [7-13]. A comprehensive review of DEA use in sports illustrates that a significant number of papers that use DEA to analyze athletic/economic/managerial efficiency in various sports have been published [14]. Both team efficiency and individual player efficiency are widely discussed across different sports, such as basketball [15], baseball [16], football [17], and tennis [18,19]. In competitions, players use different game participation strategies to obtain advantages and to avoid weakness [15]. However, to our knowledge, DEA has not yet been used in the context of game participation strategy. For this reason, evaluating game participation strategy precisely and understanding the causes of inefficiency are crucial. This not only provides an insightful perspective when discussing the efficacy of performance evaluation in sport industry but also provides practical applications for athletes to identify their strengths and to improve their winning ratios. To bridge this gap in the current literature, we propose a two-stage framework using a DEA bootstrapping methodology to develop an ITTF game participation strategy.

In the first stage, we developed an efficient game expenditure model by adopting measurable data such as local travel expenses and flight distance as input variables, and the number of points and amount of prize money won in each competition as output variables. In the second stage, we developed a prize-winning model by adopting changeable data such as the number of game participants as inputs, and the actual points and prize money won by players from TPE as output. Finally, we combined the above two models of game expenditure efficiency and prize-winning efficiency using a Boston consulting group (BCG) matrix to create a participation strategy. The results of the current study provide potential efficient game-participation recommendations for teenaged athletes, which will benefit financially challenged teenaged athletes, allowing them to choose games to optimize efficiency.

\subsection{Objectives}

We applied DEA and BCG methodologies to the 2019 ITTF World Tour with the objective of developing an efficient future game-participation strategy to increase the annual allocated points and prize money of athletes. We collected data from 2019 ITTF World Tour websites [20] and employed TPE players as our research subjects.

Our research includes the following three objectives:

(1) To analyze the game expenditure efficiency of the 2019 ITTF World Tour.

(2) To analyze the prize-winning efficiency of athletes in the 2019 ITTF World Tour.

(3) To develop a game participation strategy for the 2021 ITTF World Tour. 


\section{Methods}

In a recent study [21], researchers proposed that DEA operations include the following four stages: (1) determining the compared objectives, (2) determining the numbers of DMU, (3) selecting the inputs and outputs, and (4) applying DEA and analyzing the results. These authors noted that DEA is a method for evaluating the relative efficiency of DMUs. Homogeneity among DMUs should be strictly emphasized; otherwise, the evaluation results will not be sufficiently meaningful. As a rule of thumb, the number of evaluated units should be at least two times the sum of the inputs and outputs [21]. In DEA calculations, the respective DMUs are assigned the weights that are most beneficial in increasing their efficiency. For this reason, researcher subjectivity does not affect the weights given to DMUs in DEA.

The application of the BCG matrix is a powerful means of simplifying complex issues regarding strategy. The BCG matrix is a $2 \times 2$ matrix originally used to compare companies based on their growth rates and company shares, shown in Figure 1. Based on this data, DMUs are classified into the quadrants Stars, Dogs, Cash cows, and Question marks [22,23]. After long-term development, BCG has combined many different research methods to analyze and obtain accurate results. In previous studies, a combination of DEA and BCG was applied in the planning in UK universities [24], the evaluation of firm performance [25], and the strategic positioning of Moroccan seaports [26].

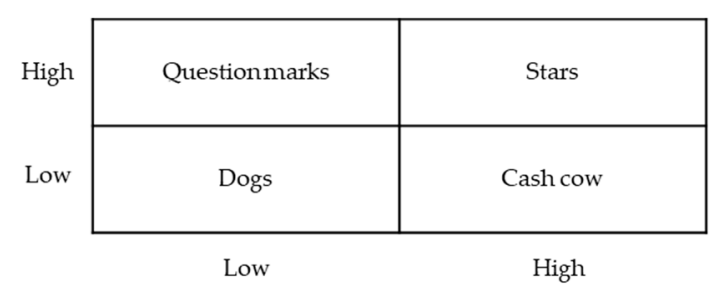

Figure 1. BCG matrix reference modified form [27].

\subsection{Statistical Analysis}

\subsubsection{DEA}

DEA is a nonparametric method for estimating production frontiers and a linear programming research method that was proposed in decision analysis and economics, developed by Charnes et al. [2]. It was used to evaluate the relative efficiency of DMUs, especially for nonprofit organizations with multiple inputs and outputs.

DEA's process to benchmark multi-dimensional inputs and outputs as well as its computational ease and quickness result from it being expressible as a linear program [28,29]. It is a very suitable method for helping players measure the performance of a particular competition. DEA defines the efficient frontier of all units under analysis and compares the estimated efficiency with the actual efficiency produced. Relative efficiency ranges between 0 and 1, with 1 being the most effective. Nonparametric methods compare feasible input and output combinations to rank DMU efficiency values and improvement goals. DEA has recently been extended to include multi-stage analyses [30,31].

We used DEAP version 2.1 software [32] for data calculation and analysis. This program is used to construct DEA frontiers for the calculation of technical and cost efficiencies. The program has CRS, VRS, and DEA models that involve the calculation of technical and scale efficiency (SE).

\subsubsection{Operational Definitions}

Table 1 presents the twelve games of the annual ITTF World Tour, including six platinum games and six regular games: the Hungarian, Qatar, China, Hong Kong, Japan, Korea, Australian, Bulgarian, Czech, Swedish, German, and Austrian Open games. 
Table 1. A summary of the 2019 ITTF World Tour event.

\begin{tabular}{|c|c|c|c|c|c|c|c|c|c|}
\hline \multirow{2}{*}{\multicolumn{2}{|c|}{ Event }} & \multicolumn{8}{|c|}{ Points (According to the Ranking) } \\
\hline & & & 1 & 2 & 3 & 8 & 16 & 32 & \\
\hline \multirow{4}{*}{ Date } & Platinum (P) & & 2250 & 1800 & 1465 & 1125 & 900 & 675 & \\
\hline & Regular (R) & & 1800 & 1440 & 1170 & 900 & 720 & 540 & \\
\hline & \multirow{2}{*}{ Location } & \multirow{2}{*}{ Event } & \multicolumn{7}{|c|}{ Prize Money (According to the Ranking) in USD } \\
\hline & & & 1 & 2 & 3 & 8 & 16 & 32 & Total \\
\hline $01 / 15-01 / 20$ & Hungary: Budapest & $\mathrm{R}$ & 18,500 & 9200 & 4500 & 2200 & 1100 & 700 & 65,500 \\
\hline $03 / 26-03 / 31$ & Qatar: Doha & $\mathrm{P}$ & 33,000 & 17,000 & 8000 & 4000 & 2500 & 1500 & 126,000 \\
\hline $05 / 28-06 / 02$ & China: Shen Zhen & $\mathrm{P}$ & 44,000 & 22,000 & 10,600 & 5900 & 3300 & 2050 & 170,000 \\
\hline $06 / 04-06 / 09$ & Hong Kong: Hong Kong & $\mathrm{R}$ & 18,600 & 9200 & 4500 & 2200 & 1200 & 800 & 68,000 \\
\hline $06 / 12-06 / 16$ & Japan: Kitakyushu & $\mathrm{P}$ & 30,000 & 15,000 & 7500 & 3750 & 2100 & 1200 & 111,000 \\
\hline $07 / 02-07 / 07$ & Korea: Busan & $\mathrm{R}$ & 16,000 & 8000 & 4000 & 2000 & 1000 & 750 & 60,000 \\
\hline $07 / 09-07 / 14$ & Australia: Geelong & $\mathrm{P}$ & 35,000 & 17,500 & 8350 & 5000 & 3000 & 1800 & 142,000 \\
\hline $08 / 13-08 / 18$ & Bulgaria: Panagyurishte & $\mathrm{R}$ & 21,000 & 10,600 & 5500 & 2800 & 1400 & 750 & 77,000 \\
\hline $08 / 20-08 / 25$ & The Czech Republic: Olomouc & $\mathrm{R}$ & 21,000 & 10,600 & 5500 & 2800 & 1400 & 750 & 77,000 \\
\hline $10 / 01-10 / 06$ & Sweden: Stockholm & $\mathrm{R}$ & 18,500 & 9200 & 4500 & 2200 & 1100 & 700 & 65,500 \\
\hline $10 / 08-10 / 13$ & Germany: Bremen & $\mathrm{P}$ & 30,000 & 15,000 & 7500 & 3750 & 2100 & 1200 & 111,000 \\
\hline $11 / 12-11 / 17$ & Austria: Linz & $\mathrm{P}$ & 30,000 & 15,000 & 7500 & 3500 & 2000 & 1000 & 106,000 \\
\hline
\end{tabular}

Based on the analysis of experts, scholars and the related literature have used the DEA methodology to analyze game efficiency [33-35]. We developed and ran an efficient game expenditure model (see Figure 2) based on foreseeable data. In this stage, we used local travel expenses and flight distances as inputs, and the number of points and the amount of prize money in each competition as output variables. In the second stage, we developed and ran a prize-winning model based on relevant variable data; we used the number of game participants as inputs, and the actual points and prize money won by players from TPE as outputs. The related operational definitions are provided in Table 2.

Table 2. Operational definitions.

\begin{tabular}{|c|c|c|}
\hline Items. & Definition & Study \\
\hline $\begin{array}{l}\text { Local travel } \\
\text { expense }\end{array}$ & $\begin{array}{l}\text { These expenses are determined based on } \\
\text { the } 2020 \text { table for the foreign per diem } \\
\text { allowance amount according to the } \\
\text { central governmental agency (USD/day) }\end{array}$ & Herrero-Prieto [36] \\
\hline Days & Match day & Hofmarcher et al. [37] \\
\hline Flight distance & $\begin{array}{l}\text { This distance is calculated from Taipei to } \\
\text { the city hosting the event }(\mathrm{km})\end{array}$ & Glass et al. [38] \\
\hline $\begin{array}{l}\text { Actual points } \\
\text { Best points }\end{array}$ & $\begin{array}{l}\text { The actual points allocated in each event } \\
\text { The champion points of each game }\end{array}$ & Sitarz [39] \\
\hline Prize money & The actual prize money of each event & Parshakov \& Zavertiaeva [40] \\
\hline $\begin{array}{l}\text { Highest prize } \\
\text { money }\end{array}$ & The champion prize money of each event & Glass et al. [38] \\
\hline Participants & Participants of each game in 2019 & Júnior et al. [41] \\
\hline Best ranking & Best ranking of each game in 2019 & Silveira Gontijo [42] \\
\hline
\end{tabular}

\subsection{Research Procedure and Data Processing}

In the first stage, we conducted an efficient game expenditure analysis. We first used the Charnes-Cooper-Rhodes (CCR) model to estimate the value of constant returns to scale technical efficiency (CRSTE) of each DMUs. CRSTE is a type of frontier scale used in DEA. It helps estimate efficiencies related to whether the inputs or outputs result in proportional changes in the corresponding outputs or inputs. We then employed the Barker-CharnesCooper (BCC) model to estimate variable returns to scale technical efficiency (VRSTE). In addition, we calculated SE by dividing CRSTE by VRSTE. The SE of the DEA parameter is the total efficiency divided by the technology. SE expresses whether the DMUs operate at 
their optimal size. If not, the next step of using further comparisons of DEA outputs (using increasing or decreasing returns to scale) determines whether the DMUs are too large or too small. Finally, slack variable analysis was applied to provide the extent to which each DMU can be improved. Slack variable analysis is an important analysis method in DEA, from which researchers can understand each DMU's potential for improvement. This is an important piece of information about what projects should be invested in future resources. The poor performance of an evaluated unit in the DMUs pushes efficiency farther away from the front line of efficiency.

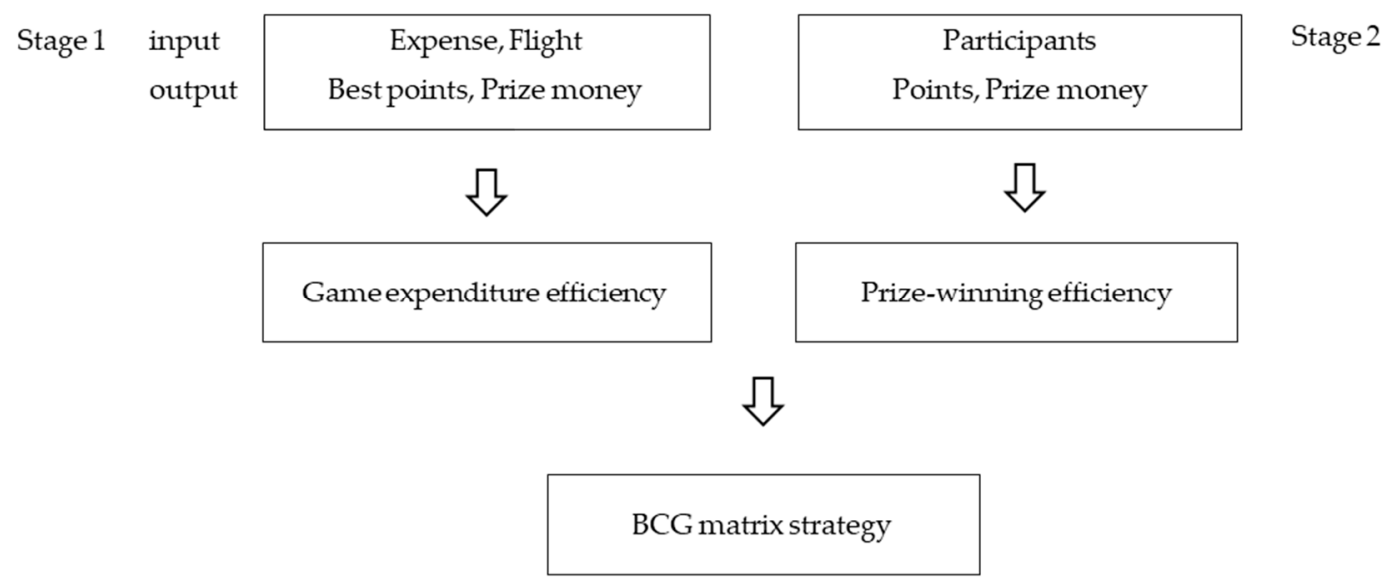

Figure 2. Conceptual framework.

In the second stage, we used the same procedures to conduct the prize-winning efficacy analysis. Finally, we combined the above two models of game expenditure efficiency and prize-winning efficiency using a BCG matrix to create a participation strategy.

We collected research data from the twelve ITTF World Tour games. A summary of the 2019 ITTF World Tour Game information is shown in Table 3. The data collected includes entrance fee (USD) for each event/game day, local travel expenses, flight distances $(\mathrm{km})$, points won, amount of prize money, number of participants, and the ranking of TPE players.

Table 3. Summary of 2019 ITTF World Tour game information.

\begin{tabular}{|c|c|c|c|c|c|c|c|c|c|}
\hline Event Location & $\begin{array}{c}\text { Entrance } \\
\text { Fee (USD) }\end{array}$ & $\begin{array}{c}\text { Daily } \\
\text { Travel } \\
\text { Expense } \\
\text { (USD) }\end{array}$ & Days & $\begin{array}{c}\text { Local } \\
\text { Travel } \\
\text { Expense }\end{array}$ & $\begin{array}{c}\text { Flight } \\
\text { Distance } \\
\text { (Km) }\end{array}$ & $\begin{array}{c}\text { Best } \\
\text { Points }\end{array}$ & $\begin{array}{c}\text { Highest } \\
\text { Prize } \\
\text { Money }\end{array}$ & Participants & $\begin{array}{c}\text { Best } \\
\text { Ranking } \\
\text { of TPE }\end{array}$ \\
\hline Hungary & 187 & 234 & 6 & 1404 & 8856 & 1800 & 18,500 & 208 & 16 \\
\hline Qatar & 207 & 290 & 6 & 1740 & 6930 & 2250 & 33,000 & 162 & 8 \\
\hline China & 207 & 180 & 6 & 1080 & 499 & 2250 & 44,000 & 153 & 32 \\
\hline Hong Kong & 187 & 308 & 6 & 1848 & 807 & 1800 & 18,600 & 131 & 32 \\
\hline Japan & 207 & 206 & 5 & 1030 & 1359 & 2250 & 30,000 & 104 & 2 \\
\hline Korea & 187 & 220 & 6 & 1320 & 1342 & 1800 & 16,000 & 124 & 32 \\
\hline Australia & 207 & 212 & 6 & 1272 & 7419 & 2250 & 35,000 & 118 & 16 \\
\hline Bulgaria & 187 & 127 & 6 & 762 & 8790 & 1800 & 21,000 & 165 & 8 \\
\hline The Czech Republic & 187 & 126 & 6 & 756 & 9029 & 1800 & 21,000 & 207 & 1 \\
\hline Sweden & 187 & 253 & 6 & 1518 & 8344 & 1800 & 18,500 & 161 & 32 \\
\hline Germany & 207 & 180 & 6 & 1080 & 9081 & 2250 & 30,000 & 199 & 32 \\
\hline Austria & 207 & 185 & 6 & 1110 & 9129 & 2250 & 30,000 & 192 & 8 \\
\hline
\end{tabular}




\section{Results}

In this section, we present the outcomes of the two stage analysis. Each stage included efficiency analysis, returns to scale analysis, and slack variable analysis. The results from the first stage represent a measure of the 2019 ITTF World Tour expenditure efficiency. The results from the second stage provide a measure of the 2019 ITTF World Tour prizewinning efficiency. Finally, we combined the two models of game expenditure efficiency and prize-winning efficiency using the BCG matrix to create a participation strategy.

\subsection{Expenditure Efficiency for the 2019 ITTF World Tour}

\subsubsection{Efficiency Analysis}

In the first stage, we conducted a game expenditure efficiency analysis using flight distances and local travel expenses as inputs; the outputs were the points won and the amount of championship prize money.

Table 4 presents the results of the efficiency analysis. We first used a CCR model to estimate the CRSTE value of each DMU, which were as follows: Hungary (0.563), Qatar (0.586), China (1), Hong Kong (0.495), Japan (1), Korea (0.635), Australia (0.796), Bulgaria (0.995), The Czech Republic (1), Sweden (0.524), Germany (0.907), and Austria (0.883).

Table 4. Expenditure efficiency for the 2019 ITTF World Tour.

\begin{tabular}{|c|c|c|c|c|c|c|c|c|c|c|}
\hline \multirow{2}{*}{\multicolumn{2}{|c|}{ Event Location }} & \multicolumn{2}{|c|}{ Input } & \multicolumn{2}{|c|}{ Output } & \multicolumn{3}{|c|}{ Efficiency } & \multirow{2}{*}{$\begin{array}{l}\text { Returns } \\
\text { to Scale }\end{array}$} & \multirow{2}{*}{$\begin{array}{c}\text { Efficiency } \\
\text { Ranking }\end{array}$} \\
\hline & & \multirow{2}{*}{$\begin{array}{c}\begin{array}{c}\text { Local } \\
\text { Travel } \\
\text { Expense }\end{array} \\
1404\end{array}$} & \multirow{2}{*}{$\begin{array}{c}\begin{array}{c}\text { Flight } \\
\text { Distance }\end{array} \\
8856\end{array}$} & \multirow{2}{*}{$\begin{array}{c}\begin{array}{c}\text { Best } \\
\text { Points }\end{array} \\
1800\end{array}$} & \multirow{2}{*}{$\begin{array}{c}\begin{array}{c}\text { Prize } \\
\text { Money }\end{array} \\
18,500\end{array}$} & \multirow{2}{*}{$\begin{array}{c}\text { CRSTE } \\
0.563\end{array}$} & \multirow{2}{*}{$\begin{array}{c}\text { VRSTE } \\
0.626\end{array}$} & \multirow{2}{*}{$\begin{array}{c}\text { SE } \\
0.899\end{array}$} & & \\
\hline Hungary & $\mathrm{R}$ & & & & & & & & Irs & 10 \\
\hline Qatar & $\mathrm{P}$ & 1740 & 6930 & 2250 & 33,000 & 0.586 & 0.598 & 0.980 & Drs & 9 \\
\hline China & $\mathrm{P}$ & 1080 & 499 & 2250 & 44,000 & 1.000 & 1.000 & 1.000 & - & 1 \\
\hline Hong Kong & $\mathrm{R}$ & 1848 & 807 & 1800 & 18,600 & 0.495 & 0.618 & 0.800 & Irs & 12 \\
\hline Japan & $\mathrm{P}$ & 1030 & 1359 & 2250 & 30,000 & 1.000 & 1.000 & 1.000 & - & 1 \\
\hline Korea & $\mathrm{R}$ & 1320 & 1342 & 1800 & 16,000 & 0.635 & 0.793 & 0.800 & Irs & 8 \\
\hline Australia & $\mathrm{P}$ & 1272 & 7419 & 2250 & 35,000 & 0.796 & 0.824 & 0.966 & Drs & 7 \\
\hline Bulgaria & $\mathrm{R}$ & 762 & 8790 & 1800 & 21,000 & 0.995 & 1.000 & 0.995 & Irs & 4 \\
\hline $\begin{array}{l}\text { The Czech } \\
\text { Republic }\end{array}$ & $\mathrm{R}$ & 756 & 9029 & 1800 & 21,000 & 1.000 & 1.000 & 1.000 & - & 1 \\
\hline Sweden & $\mathrm{R}$ & 1518 & 8344 & 1800 & 18,500 & 0.524 & 0.593 & 0.884 & Irs & 11 \\
\hline Germany & $\mathrm{P}$ & 1080 & 9081 & 2250 & 30,000 & 0.907 & 0.954 & 0.951 & Drs & 5 \\
\hline Austria & $\mathrm{P}$ & 1110 & 9129 & 2250 & 30,000 & 0.883 & 0.928 & 0.952 & Drs & 6 \\
\hline mean & & 1243 & 5965 & 2025 & 26,300 & 0.782 & 0.828 & 0.936 & & \\
\hline
\end{tabular}

CRSTE: constant returns to scale technical efficiency. VRSTE: variable returns to scale technical efficiency. SE: scale efficiency.

We then employed the BCC model to estimate VRSTE. The VRSTEs of the various DMUs were as follows: Hungary (0.626), Qatar (0.598), China (1), Hong Kong (0.618), Japan (1), Korea (0.793), Australia (0.824), Bulgaria (1), The Czech Republic (1), Sweden (0.593), Germany (0.954), and Austria (0.928).

From the findings, we calculated SE by dividing CRSTE by VRSTE. Based on these calculations, we found that the China Open, Japan Open, and Czech Open had SEs of 1. For both CRTSE and SE, the Bulgarian Open obtained a value of 0.995, which fell slightly short of the efficiency frontier.

\subsubsection{Returns to Scale Analysis}

In stage 1 of the returns to scale analysis, the China Open, Japan Open, and Czech Open reached the efficiency frontier. The CCR model hypothesizes that, under constant returns to scale, we can calculate the relative efficiencies of the DMUs. Inefficient DMUs can result from the different scales of the games. When the constant SE does not reach 1 , this result implies an increase or decrease in SE. 


\subsubsection{Slack Variable Analysis}

A slack variable analysis mainly targets inefficient DMUs to identify which variables need improvement. In general, the identification of a slack variable in the input category indicates an excessive investment of resources; the identification of a slack variable in the output category indicates that improvements in that variable could result in higher efficiencies. We conducted a slack variable analysis on the twelve 2019 ITTF World Tour games, and the results are presented in Table 5.

Table 5. Suggested input efficiency targets for the 2019 ITTF World Tour.

\begin{tabular}{ccccccc}
\hline \multirow{2}{*}{$\begin{array}{c}\text { Event } \\
\text { Location }\end{array}$} & \multicolumn{2}{c}{ Local Travel Expense (USD) } & \multicolumn{3}{c}{ Flight Distance (Km) } \\
\cline { 2 - 6 } & Original & Suggested & Difference & Original & Suggested & Difference \\
\hline Hungary & 1404 & 879 & 525 & 8856 & 5545 & 3311 \\
Qatar & 1740 & 1040 & 700 & 6930 & 1175 & 5755 \\
Hong Kong & 1848 & 1808 & 40 & 807 & 499 & 308 \\
Korea & 1320 & 1047 & 273 & 1342 & 1064 & 278 \\
Australia & 1272 & 1048 & 224 & 7419 & 1051 & 6368 \\
Bulgaria & 762 & 762 & 0 & 8790 & 8790 & 0 \\
Sweden & 1518 & 900 & 618 & 8344 & 4950 & 3394 \\
Germany & 1080 & 1030 & 50 & 9081 & 1359 & 7722 \\
Austria & 1110 & 1030 & 80 & 9129 & 1359 & 7770 \\
\hline
\end{tabular}

The inputs (original values) were local travel expenses (USD) and flight distances $(\mathrm{km})$. The outputs were the championship prize money and points. Both inputs and outputs were constant. Using slack variable analysis, we obtained a suggested value for each variable [43]. We calculated the difference values by subtracting the suggested values from the original values. When input values are reduced, efficiency reaches the optimal efficiency frontier.

The Bulgarian Open had an efficiency of 0.995; thus, suggested values for local travel expenses and flight distances remained the same. The German Open had an efficiency of 0.907. Local travel expenses were 1080 USD, and the suggested target was 1030 USD, for a difference of 50 USD. The flight distance was $9081 \mathrm{~km}$, and the suggested target was $1359 \mathrm{~km}$, for a difference of $7722 \mathrm{~km}$. The Austrian Open had an efficiency of 0.883 . Local travel expenses were 1110 USD, and the suggested target was 1030 USD, for a difference of 80 USD. The flight distance was $9129 \mathrm{~km}$, and the suggested target was $1359 \mathrm{~km}$, for a difference of $7770 \mathrm{~km}$. The Australian Open had an efficiency of 0.796. Local travel expenses were 1272 USD, and the suggested target was 1048 USD, for a difference of 224 USD. The flight distance was $7419 \mathrm{~km}$, and the suggested target was $1051 \mathrm{~km}$, for a difference of $6368 \mathrm{~km}$.

\subsection{Prize-Winning Efficiency for the 2019 ITTF World Tour}

\subsubsection{Efficiency Analysis}

In the second stage, we calculated the prize-winning efficiency using the actual number of players and local travel expenses as inputs; the outputs were points and the championship prize money.

Table 6 presents the results of the prize-winning efficiency analysis for the twelve ITTF World Tour games. We first used a CCR model to estimate the following CRSTEs for the various DMUs: Hungary (0.200), Qatar (0.401), China (0.255), Hong Kong (0.238), Japan (1), Korea (0.252), Australia (0.441), Bulgaria (0.315), The Czech Republish (703), Sweden (0.194), Germany (0.196), and Austria (0.339). 
We then employed the BCC model to estimate the VRSTE, which were as follows: Hungary (0.400), Qatar (0.625), China (0.375), Hong Kong (0.3), Japan (1), Korea (0.3), Australia (0.5), Bulgaria (0.5), The Czech Republic (1), Sweden (0.3), Germany (0.375), and Austria (0.625).

Based on these findings, we calculated the SE by dividing CRSTE by VRSTE. According to the calculation, we found out that the Japan Open was the only game to reach an SE of 1 .

In conclusion, the Japan Open was the only game to reach a total technical efficiency of 1 in the CCR model. The BCC model showed that both the Japan Open and Czech Open achieved a pure technical efficiency of 1 . SE was obtained by dividing total efficiency by technical efficiency. The Japan Open was the only game to reach an SE of 1.

Table 6. Prize-winning efficiency for the 2019 ITTF World Tour.

\begin{tabular}{|c|c|c|c|c|c|c|c|c|}
\hline \multirow[b]{2}{*}{ Event Location } & \multirow{2}{*}{$\begin{array}{c}\text { Input } \\
\text { Participants }\end{array}$} & \multicolumn{2}{|c|}{ Output } & \multicolumn{3}{|c|}{ Efficiency } & \multirow[b]{2}{*}{$\begin{array}{c}\text { Returns to } \\
\text { Scale }\end{array}$} & \multirow[b]{2}{*}{$\begin{array}{c}\text { Efficiency } \\
\text { Ranking }\end{array}$} \\
\hline & & $\begin{array}{l}\text { Actual } \\
\text { Points }\end{array}$ & $\begin{array}{l}\text { Prize } \\
\text { Money } \\
\text { (USD) }\end{array}$ & CRSTE & VRSTE & SE & & \\
\hline Hungary & 208 & 720 & 1100 & 0.200 & 0.400 & 0.500 & drs & 10 \\
\hline Qatar & 162 & 1125 & 4000 & 0.401 & 0.625 & 0.642 & drs & 4 \\
\hline China & 153 & 675 & 2050 & 0.255 & 0.375 & 0.680 & drs & 7 \\
\hline Hong Kong & 131 & 540 & 800 & 0.238 & 0.300 & 0.794 & drs & 9 \\
\hline Japan & 104 & 1800 & 15,000 & 1.000 & 1.000 & 1.000 & - & 1 \\
\hline Korea & 124 & 540 & 750 & 0.252 & 0.300 & 0.839 & drs & 8 \\
\hline Australia & 118 & 900 & 3000 & 0.441 & 0.500 & 0.881 & drs & 3 \\
\hline Bulgaria & 165 & 900 & 2800 & 0.315 & 0.500 & 0.630 & drs & 6 \\
\hline The Czech Republic & 207 & 1800 & 21,000 & 0.703 & 1.000 & 0.703 & drs & 2 \\
\hline Sweden & 161 & 540 & 700 & 0.194 & 0.300 & 0.646 & drs & 12 \\
\hline Germany & 199 & 675 & 1200 & 0.196 & 0.375 & 0.523 & drs & 11 \\
\hline Austria & 192 & 1125 & 3500 & 0.339 & 0.625 & 0.542 & drs & 5 \\
\hline mean & 160 & 945 & 4658 & 0.378 & 0.525 & 0.698 & & \\
\hline
\end{tabular}

CRSTE: constant returns to scale technical efficiency. VRSTE: variable returns to scale technical efficiency. SE: scale efficiency.

\subsubsection{Returns to Scale Analysis}

According to the returns to scale analysis, the Japan Open achieved an SE of 1 and reached the optimal efficiency frontier. The other eleven games showed a decreasing return to scale.

\subsubsection{Slack Variable Analysis}

The outputs of the 2019 ITTF World Tour games were the prize money won and the points allocated. For efficiency, the outputs should be our main objective since the input, which is the actual number of contestants participating in games, cannot be predicted.

Table 7 presents the slack variable analysis of the games for which the efficiency did not reach 1 . The Czech Open had an efficiency of 0.703 , ranking second in efficiency. The original allocated points and prize money remained the same in the suggested values. For the Australian Open, the number of points increased from 900 to 1800, for a difference of 900. The championship prize money increased from 3000 USD to 15,816 USD, for a difference of 12,816 USD. For the Qatar Open, the number of points increased from 1125 to 1800 , for a difference of 675 . The championship prize money increased from 4000 USD to 18,379 USD, for a difference of 14,379 USD. For the Austrian Open, the number of points increased from 1125 to 1800 , for a difference of 675 . The championship prize money increased from 3500 USD to 18,500 USD, for a difference of 15,000 USD. 
Table 7. Suggested output efficiency targets for the 2019 ITTF World Tour.

\begin{tabular}{|c|c|c|c|c|c|c|c|c|}
\hline \multirow{2}{*}{$\begin{array}{c}\text { Event } \\
\text { Location }\end{array}$} & \multicolumn{4}{|c|}{ Points } & \multicolumn{4}{|c|}{ Prize Money } \\
\hline & Champion & Original & Suggested & Difference & Champion & Original & Suggested & Difference \\
\hline Hungary & 1800 & 720 & 1800 & 1080 & 18,500 & 1100 & * 18,500 & 17,400 \\
\hline Qatar & 2250 & 1125 & 1800 & 675 & 33,000 & 4000 & 18,379 & 14,379 \\
\hline China & 2250 & 675 & 1800 & 1125 & 44,000 & 2050 & 17,854 & 15,804 \\
\hline Hong Kong & 1800 & 540 & 1800 & 1260 & 18,600 & 800 & 16,573 & 15,773 \\
\hline Korea & 1800 & 540 & 1800 & 1260 & 16,000 & 750 & * 16,000 & 15,250 \\
\hline Australia & 2250 & 900 & 1800 & 900 & 35,000 & 3000 & 15,816 & 12,816 \\
\hline Bulgaria & 1800 & 900 & 1800 & 900 & 21,000 & 2800 & 18,553 & 15,753 \\
\hline Czech & 1800 & 1800 & 1800 & 0 & 21,000 & 21,000 & 21,000 & 0 \\
\hline Sweden & 1800 & 540 & 1800 & 1260 & 18,500 & 700 & 18,320 & 17,620 \\
\hline Germany & 2250 & 675 & 1800 & 1125 & 30,000 & 1200 & 20,534 & 19,334 \\
\hline Austria & 2250 & 1125 & 1800 & 675 & 30,000 & 3500 & 18,500 & 15,000 \\
\hline
\end{tabular}

* Remarks: The suggested prize money for the Hungarian Open and the Korea Open were both higher than the champion prize money. Therefore, the revised suggested prize money for the Hungarian Open was 18,500 USD and the revised suggested prize money for the Korea Open was 16,000 USD.

\subsection{Game Participation Strategy for the 2021 ITTF World Tour}

According to the first stage of the current study presented in Table 4, we conducted a game expenditure efficiency analysis using the CCR, CRSTE, and BCC models. Table 8 presents the results. The results revealed that the top four games were the China Open (1), Japan Open (1), Czech Open (1), and Bulgarian Open (0.995).

In the second stage, we conducted a prize-winning efficiency analysis to identify the optimal efficiency of each DMU. The results indicated that the top four games, from the highest to the lowest, were the Japan Open (1), Czech Open (0.703), Australian Open (0.441), and Qatar Open (0.401).

We then applied a BCG matrix to the results of DEA in the 2019 ITTF World Tour game participation (see Figure 3). Based on the BCG matrix, the games fell into four categories:

Stars stands for high tour expenditure efficiency, high prize-winning efficiency, and high profits games. We should continue to participate in such games. The Stars games were the Japan Open, Czech Open, and the Australian Open.

Cash cows stands for high tour expenditure efficiency with extremely poor market prize-winning efficiency. It is necessary to think carefully before participating and to trace the root cause of the problem. The Cash cow games were the China Open, Bulgarian Open, German Open, and the Austrian Open.

Question mark represents low tour expenditure efficiency with high prize-winning efficiency performance. This occurs in a relatively good external environment situation, thus resulting in high performance. The Question mark game was Qatar Open.

Dog represents low expenditure efficiency and low prize-winning efficiency. Such games are in a state of uncertainty, and we must review the potential problems affecting performance. The Dog games were the Hungarian Open, Hong Kong Open, Korea Open, and the Swedish Open. 
Table 8. Game participation strategy for the 2021 ITTF World Tour.

\begin{tabular}{cccc}
\hline Event Location & $\begin{array}{c}\text { First Stage Efficiency } \\
\text { (Ranking) }\end{array}$ & $\begin{array}{c}\text { Second Stage Efficiency } \\
\text { (Ranking) }\end{array}$ & $\begin{array}{c}\text { BCG } \\
\text { Matrix }\end{array}$ \\
\hline Hungary & $0.563(10)$ & $0.200(10)$ & Dog \\
Qatar & $0.586(9)$ & $0.401(4)$ & Question mark \\
China & $1.000(1)$ & $0.255(7)$ & Cash cows \\
Hong Kong & $0.495(12)$ & $0.238(9)$ & Dog \\
Japan & $1.000(1)$ & $1.000(1)$ & Stars \\
Korea & $0.635(8)$ & $0.252(8)$ & Dog \\
Australia & $0.796(7)$ & $0.441(3)$ & Stars \\
Bulgaria & $0.995(4)$ & $0.315(6)$ & Cash cows \\
The Czech Republic & $1.000(1)$ & $0.703(2)$ & Stars \\
Sweden & $0.524(11)$ & $0.194(12)$ & Dog \\
Germany & $0.907(5)$ & $0.196(11)$ & Cash cows \\
Austria & $0.883(6)$ & $0.339(5)$ & Cash cows \\
mean & 0.782 & 0.378 & \\
\hline
\end{tabular}

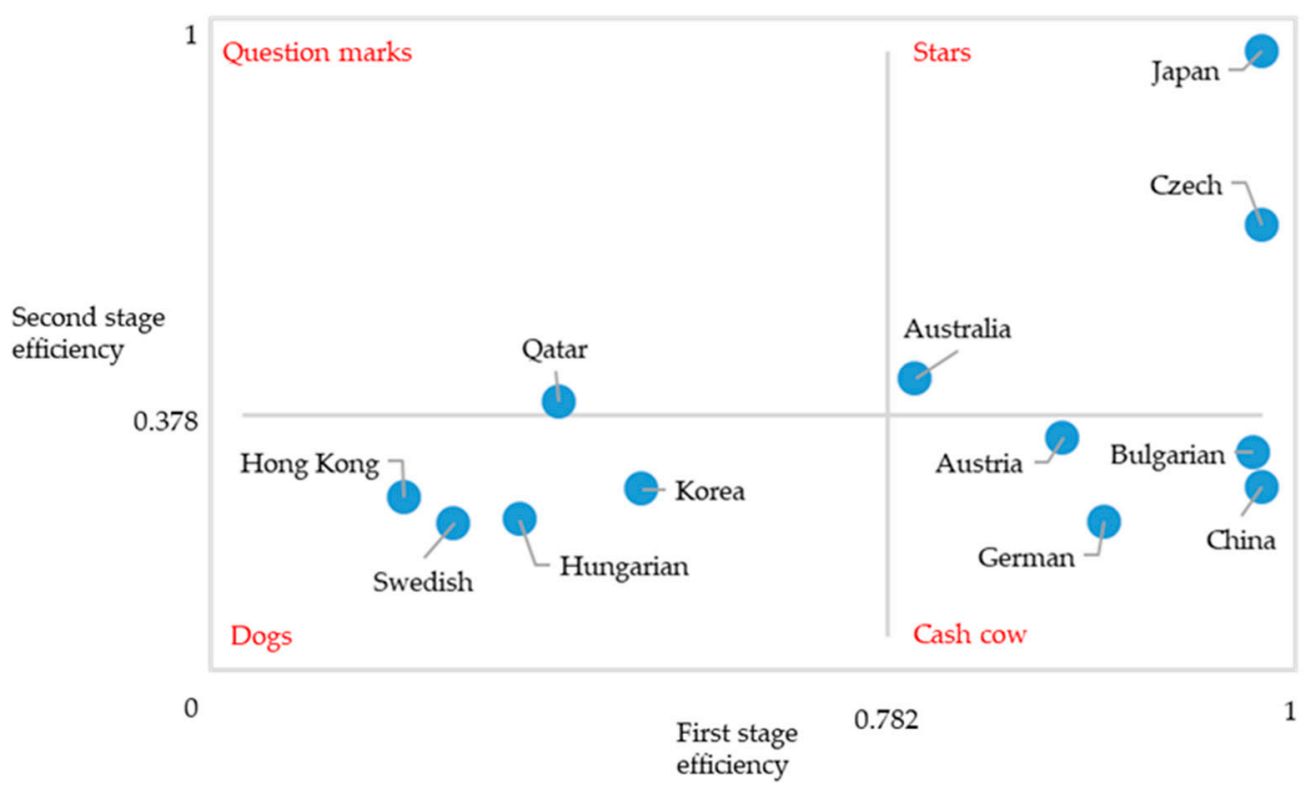

Figure 3. Game BCG matrix for the 2021 ITTF World Tour.

\section{Discussion}

\subsection{Discussion of the 2019 ITTF World Tour Expenditure Analysis}

\subsubsection{Game Expenditure Efficiency}

Based on our analysis, the China Open and the Japan Open were the platinum games with the highest efficiency. The China Open had the highest championship prize money out of all twelve games: 44,000 USD. The Japan Open had the fourth highest championship prize money: 30,000 USD. The two games shared similarities, such as short fight distances and locations within Asia. The Japan Open had higher travel expenses, but the game duration was only 5 days, resulting in local travel expenses of 1030 USD (third lowest). The other eleven games all had durations of 6 days. The China Open had local travel expenses of 1080 USD (fourth lowest); therefore, the expenditure analysis of the platinum games showed that the China Open and Japan Open had the highest efficiency.

The Czech Open was the only game out of the ITTF World Tour regular games to reach efficiency. For the Czech Open, the flight distance was $9029 \mathrm{~km}$ (third longest distance), and the championship prize money was 21,000 USD. However, local travel expenses were 756 USD, the lowest out of all twelve World Tour games, which facilitated the Czech Open in being the only game out of the ITTF World Tour regular games to reach efficiency. 
The Bulgarian Open had the same number of points and amount of championship prize money won as the Czech Open, i.e., 1800 points and 21,000 USD, respectively. However, the Czech Open had a shorter flight distance of $8790 \mathrm{~km}$. The Bulgarian Open fell slightly short of the optimal efficiency frontier, with an efficiency of 0.995; thus, participation was recommended. Regarding expenditure, the top four games with the highest efficiency, from lowest to highest, were the Czech Open, Bulgarian Open, Japan Open, and China Open. The Japan Open had a shorter game duration of 5 days and lower local travel expenses. We found that lower local travel expenses significantly increased the expenditure efficiency of games. Mokhtarian and Chen [44] noted that money spent on travel reduced travel expenses due to reduced working days, which was consistent with our findings in this article. Therefore, players can choose to compete in countries with games that last fewer days to improve overall efficiency.

In conclusion, the World Tour games with the highest expenditure efficiencies were the China Open (platinum), Japan Open (platinum), and Czech Open (regular).

\subsubsection{Slack Variable Analysis}

The slack variable analysis mainly targeted inefficient DMUs to identify which variables could be improved. In terms of local travel expenses and flight distances, the China Open, Japan Open, and Czech Open had the highest efficiencies. The Bulgarian Open also had a high efficiency because the suggested values for both local travel expenses and the flight distance were the same as the actual values. The German Open (0.907) and Austrian Open (0.883) ranked fifth and sixth in efficiency.

We found interesting results when comparing the German Open with the Austrian Open. The flight distance from TPE to Germany $(9081 \mathrm{~km})$ and Austria (9129) was similar; however, the efficiency value of the German Open was 0.907, which was better than that of the Austrian Open (0.883). The key difference between the two efficacy values was local travel expenses. The local travel expenses for the Austrian Open exceeded those of the German Open by 30 USD. Therefore, the efficiency of the Austrian Open was slightly lower than that of the German Open. Based on the slack variable analysis, we determined that athletes from TPE should consider local price levels more than flight distance when deciding which ITTF games to attend, as doing so enhances efficiency and reduces expenditure. Park et al. [45] noted that, in Asian countries, tourists who visit South Korea and Hong Kong for the same number of days usually spend more money due to the high local travel expenses in South Korea and Hong Kong. This finding is consistent with our research results. Due to high local travel expenses, the overall efficiency values for the Korea and Hong Kong Opens rank 9th and 10th among the twelve opens, despite their locations near Taipei. This finding verifies that the local travel expenses are an important factor in efficiency. In conclusion, local travel expenses impacted efficiency more than did flight distances.

\subsection{Discussion of the 2019 ITTF World Tour Prize-Winning Analysis}

\subsubsection{Prize-Winning Efficiency}

According to our findings, the Japan Open had the highest prize-winning efficiency among the platinum games. The number of contestants was 104, which was the fewest participants of the twelve ITTF World Tour games. Fewer contestants may be beneficial for our young players' performances. In addition, the similarity in food and weather between Japan and Taipei may also have contributed to TPE players outstanding performances. In a prior study, Voltaire et al. [46] reported that maintaining normal daily eating habits can help athletes perform in their best condition in competitions in different climates and countries. Therefore, choosing to participate in ITTF games in countries with similar geographical environments, food, and cultures might help players maintain better athletic status. This will profoundly improve the efficiency of winning.

The Czech Open prize-winning efficiency ranked second of all the games. According to the 2021 ITTF website [20], in 2018 and 2019, the world's top three ranking players 
did not participate in the Czech Open, thus likely increasing the TPE players' odds of winning. The Australian Open, with 118 participants, had the third highest efficiency. Even though the points and prize money obtained were not as high as those obtained at the Qatar Open (162 participants; ranked 4th; 1125 points and 4000 USD) or the Austrian Open (192 participants; ranked 5th; 1125 points and 3500 USD), there were fewer contestants in the Australian Open, giving it better efficiency.

In conclusion, the Japan Open and Australian Open had the fewest participants, leading to higher game winning efficiencies. Notably, the Czech Open had the same points and prize money as the Japan Open. However, the Czech Open had 207 participants, which was almost double that of the Japan Open (104 players). We can easily observe that the fewer participants produced higher efficiencies. Additionally, players can target the games in which the top three world ranking players did not participate to achieve higher efficiency.

\subsubsection{Slack Variable Analysis}

The slack variable analysis targeted the points and prize money won in the twelve ITTF World Tour games. Ten games did not reach optimal efficiency; the Japan Open and Czech Open, which possessed high efficiency, were the exceptions. Therefore, the slack variable analysis focused on the games that ranked third to sixth: the Australian Open (0.441), Qatar Open (0.401), Austrian Open (0.339), and Bulgarian Open (0.315).

In the Australian Open, a TPE player finished sixteenth in the finals, winning 900 points. The suggested points were 1800 points, with a difference of 900 points. The prize money won was 3000 USD, and the suggested amount was 15,816 USD, with a difference of 12,816 USD. To achieve the highest efficiency, participants should win at least second place.

In the Qatar Open (platinum), a TPE player reached the quarter finals, acquiring 1125 points. The suggested points were 1800 points, for a difference of 675 points. The prize money won was 4000 USD, and the suggested amount was 18,379 USD, for a difference of 14,379 USD. To reach efficiency, the championship must be won because the suggested prize money $(18,379$ USD) was more than the prize money awarded for second place (17,000 USD).

In conclusion, although the suggested points for the two games noted above were 1800 , which is equivalent to second place, only the Australian Open can achieve efficiency if a player wins second place. In the other three games, the championship must be won to achieve efficiency. For this reason, pregame analysis and goal planning should be greatly emphasized. A past study [47] also revealed that athletes who have clear sport goals and the determination to refine their skills have a better chance of achieving sport goals during practice and competitions. Accordingly, we suggest that the numbers of participants participating in each game should be gathered annually to provide clear information to teenaged athletes.

\subsection{Discussion of the 2021 ITTF World Tour Game Participation Strategy}

As the 2020 competition year was affected by the coronavirus disease (COVID-19), our study adopted the 2019 ITTF data to develop a participation strategy for the 2021 ITTF World Tour games. In the BCG matrix analysis, all games were distributed into four quadrants. A future competition strategy can be formulated based on where the games are located in the matrix. The Stars quadrant is the most efficient and cost-effective for competition. For efficiency-rewarding games, players must be prepared to participate in the competition in top condition. Players should carefully consider participation in games in the Cash cows quadrant when resources are limited. According to our findings, the optimal game participation strategy includes the following sequence: 1. Japan Open, 2. Czech Open, 3. Australian Open, 4. Bulgarian Open, 5. Austrian Open, 6. China Open, 7. German open, 8. Qatar open, 9. Korea Open. 10. Hong Kong Open, 11. Hungarian Open, and 12. Swedish Open. 
As reflected in the above ranking, the Swedish Open had the lowest efficiency. Participants in the Swedish Open may spend more on travel due to high local travel expenses. In addition, according to the 2021 ITTF website [20], the Swedish Open will be held just 2 days after the German Open finishes. Players who compete in both the German and Swedish Opens are unlikely to maintain top conditions. A past study illustrated the importance of the game schedule. Knust [48] used local searches and genetic algorithms to analyze the game schedules of amateur table tennis leagues. The author discovered that a poorly organized game schedule could cause significant increases in expenditures of resources and time. Additionally, short intervals between games increases bodily fatigue and affects the performance of athletes. Duran, Duran, Marenco, Mascialino, and Rey [49] used an operations research perspective to analyze the annual game schedule of the Argentina Basketball League. Their research increased equality in team schedules and reduced the average flight time for each team by at least 30\%. Table tennis athletes should also consider game dates to maintain the best conditions, to achieve higher points, and to win more prize money.

One TPE player made a wise choice by choosing to play in the Czech Open (second highest ranking) instead of the Bulgarian Open (fourth highest ranking), which were held around the same time. The TPE player not only performed well in the Czech Open but also spent less than would have been required for the Bulgarian Open. The TPE player's game participation strategy was consistent with our analysis, constituting one of the major discoveries of our research.

The Japan Open (platinum) had the highest ranking, and the TPE player won second place. We strongly recommend the Japan Open because of the short flight, short game duration (5 days), and lower number of contestants. The Czech Open (regular) had the second highest ranking, and the athlete from TPE won the championship. The Australian Open (platinum) had the third highest ranking, and the TPE player finished eighth in the finals. The lower number of participants, and higher points and prize money of the Australian Open (platinum) resulted in its recommendation.

Teenage athletes often face the dilemma of whether to become professional athletes. They are also limited by insufficient funding. The findings of the present research provide teenaged athletes with clear efficiency information on all ITTF World Tour games. For games with similar locations, points, and prize money, game with shorter durations had higher efficiencies; if game durations were the same, choosing to compete in countries with lower local travel expenses produced higher efficiency. For all game events, three main factors should be observed beforehand to increase efficiency. First, players should gauge whether the geographical environment and food culture are similar to that of their country. Second, players should observe the number of participants in previous years. Third, players should focus on whether the top three world ranking players have recently participated in the game.

\section{Conclusions and Recommendations}

Our research applied the DEA and BCG bootstrapping methodologies to the 2019 ITTF World Tour to develop an efficient future game participation strategy to increase the annual allocated points and prize money of athletes. The conclusions and recommendations are as follows.

\subsection{Conclusions}

We observed that, regardless of the distance to the game location, calculating travel expenses and local price levels benefits efficiency and should thus be the first consideration. This research is practically beneficial for teenage athletes when choosing which games to participate in based on limited resources.

As the 2020 competition year was affected by COVID-19, this analysis was based on the 2019 ITTF World Tour games and was intended to help TPE players develop a 2021 game participation strategy. Our efficiency-based suggested participation sequence is as 
follows: the Japan Open, Czech Open, Australian Open, Bulgarian Open, Austrian Open, China Open, and German Open.

\subsection{Recommendations}

Some limitations affect the interpretation of our findings. First, we only employed data from the 2019 ITTF World Tour to develop game expenditure efficacy and a prize-winning efficacy analysis. Future studies should collect longitudinal annual records to provide clear information for teenaged athletes. Second, our study only collected data from TPE table-tennis players. We recommend that DEA and BCG models are applied to other sports to benefit teenaged athletes in all countries when choosing games to participate in. This research is practically beneficial for teenage athletes choosing which games to participate in based on limited resources.

Author Contributions: Methodology, Y.-C.C., and L.-H.H.; software, Y.-C.C. and L.-H.H.; validation, Y.-C.C.; formal analysis, Y.-C.C. and J.-J.Y.; investigation, Y.-C.C.; resources, W.C.L.; data curation, Y.-C.C. and J.-J.Y.; writing - original draft preparation, Y.-C.C. and J.-J.Y.; writing-review and editing, L.-H.H., W.C.L. and J.-Z.W.; project administration, L.-H.H. and J.-Z.W. All authors have read and agreed to the published version of the manuscript.

Funding: This study is partially supported by the Ministry of Science and Technology, Taiwan (MOST108-2911-I-031-502; MOST108-2221-E-031-001-MY2) and the Center for Applied Artificial Intelligence Research, Soochow University, Taiwan (C-01).

Institutional Review Board Statement: Not applicable.

Informed Consent Statement: Not applicable.

Data Availability Statement: Not applicable.

Conflicts of Interest: The authors declare no conflict of interest.

\section{References}

1. Farrell, M.J. The Measurement of Productive Efficiency. J. R. Stat. Soc. Ser. A 1957, 120, 253-290. [CrossRef]

2. Charnes, A.; Cooper, W.W.; Rhodes, E. Measuring the efficiency of decision making units. Eur. J. Oper. Res. 1978, 2, 429-444. [CrossRef]

3. Banker, R.D.; Charnes, A.; Cooper, W.W. Some Models for Estimating Technical and Scale Inefficiencies in Data Envelopment Analysis. Manag. Sci. 1984, 30, 1078-1092. [CrossRef]

4. Larissa, B.; Maran, R.M.; Ioan, B.; Anca, N.; Mircea-Iosif, R.; Horia, T.; Gheorghe, F.; Speranta, M.E.; Dan, M.I. Adjusted Net Savings of CEE and Baltic Nations in the Context of Sustainable Economic Growth: A Panel Data Analysis. J. Risk Financ. Manag. 2020, 13, 234. [CrossRef]

5. Bătrâncea, L.; Nichita, A. Which is the best government? Colligating tax compliance and citizens' insights regarding authorities' actions. Transylv. Rev. Adm. Sci. 2015, 11, 5-22.

6. Ruiz, J.L.; Pastor, D.; Pastor, J.T. Assessing Professional Tennis Players Using Data Envelopment Analysis (DEA). J. Sports Econ. 2011, 14, 276-302. [CrossRef]

7. Guzmán, I. Measuring Efficiency and Sustainable Growth in Spanish Football Teams. Eur. Sport Manag. Q. 2006, 6, 267-287. [CrossRef]

8. Hu, L.H.; Kang, C.N. The efficiency analysis of the CPBL players before and after the signing of mul-ti-year-contracts. Phys. Educ. J. 2019, 52, 95-107. [CrossRef]

9. Lewis, H.F.; Sexton, T.R.; Lock, K.A. Player Salaries, Organizational Efficiency, and Competitiveness in Major League Baseball. J. Sports Econ. 2007, 8, 266-294. [CrossRef]

10. Lin, W.B. An Application of the Metafrontier and Technical Gap Ratio in Sport. Phys. Educ. J. 2015, 48, 383-398. [CrossRef]

11. Lin, C.-H. Effects of Different Ball Size and Ability on Table Tennis Backhand Block Learning. Sports Exerc. Res. 2013, 15, 269-276. [CrossRef]

12. Meza, L.A.; Valério, R.P.; De Mello, J.C.C.S. Assessing the Efficiency of Sports in Using Financial Resources with DEA Models. Procedia Comput. Sci. 2015, 55, 1151-1159. [CrossRef]

13. Volz, B. Minority Status and Managerial Survival in Major League Baseball. J. Sports Econ. 2009, 10, 522-542. [CrossRef]

14. Bhat, Z.U.H.; Sultana, D.; Dar, Q.F. A comprehensive review of data envelopment analysis (DEA): Approach in sports. J. Sports Econ. Manag. 2019, 9, 82-109. 
15. Cooper, W.W.; Ramón, N.; Ruiz, J.L.; Sirvent, I. Avoiding large differences in weights in cross-efficiency evaluations: Ap-plication to the ranking of basketball players. J. Cent. Cathedra Bus. Econ. Res. J. 2011, 4, 197-215. [CrossRef]

16. Miceli, T.J.; Volz, B.D. Debating Immortality: Application of Data Envelopment Analysis to Voting for the Baseball Hall of Fame. Manag. Decis. Econ. 2012, 33, 177-188. [CrossRef]

17. Kulikova, L.I.; Goshunova, A.V. Efficiency measurement of professional football clubs: A non-parametric approach. Life Sci. J. 2014, 11, 117-122.

18. Chitnis, A.; Vaidya, O. Performance Assessment of Tennis Players: Application of DEA. Procedia Soc. Behav. Sci. 2014, 133, 74-83. [CrossRef]

19. Chmait, N.; Westerbeek, H.; Eime, R.; Robertson, S.; Sellitto, C.; Reid, M. Tennis influencers: The player effect on social media engagement and demand for tournament attendance. Telemat. Inform. 2020, 50, 101381. [CrossRef]

20. International Table Tennis Federation, ITTF Table Tennis World Ranking. Available online: https://www.ittf.com/rankings/ (accessed on 22 June 2021).

21. Golany, B.; Roll, Y. An application procedure for DEA. Omega 1989, 17, 237-250. [CrossRef]

22. Morrison, A.; Wensley, R. Boxing up or Boxed in A Short History of the Boston Consulting Group Share/Growth Matrix. J. Mark. Manag. 1991, 7, 105-129. [CrossRef]

23. Mut, E.; Kanuma, N.T.; Rusatira, E.; Kwiringirimana, T.; Mugenzi, P.; Govere, I.; Foti, R. Analysis of coffee export mar-keting in Rwanda: Application of the Boston consulting group matrix. Afr. J. Bus. Manag. 2009, 3, 210-219. [CrossRef]

24. Sarrico, C.S.; Dyson, R.G. Using DEA for planning in UK universities-an institutional perspective. J. Oper. Res. Soc. 2000, 51, 789-800. [CrossRef]

25. Wang, Y.; Li, Y.; Jan, C.; Chang, K. Evaluating firm performance with balanced scorecard and data envelopment analysis. Wseas. Trans. Bus. Econ. 2013, 10, 24-39.

26. Birafane, M.; Liu, W.; Khalikov, S. The Strategic Positioning of Moroccan Seaports: An Application of the Boston Consulting Group Growth-share Matrix. Open Transp. J. 2020, 14, 133-142. [CrossRef]

27. Hambrick, D.C. Environmental scanning and organizational strategy. Strat. Manag. J. 1982, 3, 159-174. [CrossRef]

28. Morita, H.; Hirokawa, K.; Zhu, J. A slack-based measure of efficiency in context-dependent data envelopment analysis. Omega 2005, 33, 357-362. [CrossRef]

29. Sickles, R.C.; Zelenyuk, V. Measurement of Productivity and Efficiency; Cambridge University Press (CUP): Cambridge, UK, 2019.

30. Chen, C.-H.; Lin, W.-B.; Yang, S.-C.; Hsiao, R. Multiple Criteria Decision-Making: A Novel Applications of Network DEA Model. Processes 2020, 8, 1482. [CrossRef]

31. Wang, C.-N.; Tsai, H.-T.; Ho, T.-P.; Nguyen, V.-T.; Huang, Y.-F. Multi-Criteria Decision Making (MCDM) Model for Supplier Evaluation and Selection for Oil Production Projects in Vietnam. Processes 2020, 8, 134. [CrossRef]

32. Coelli, T. A guide to DEAP version 2.1: A data envelopment analysis (computer) program. Cent. Effic. Product. Anal. 1996, $96,1-49$.

33. Guzmán, I.; Morrow, S. Measuring efficiency and productivity in professional football teams: Evidence from the English Premier League. Cent. Eur. J. Oper. Res. 2007, 15, 309-328. [CrossRef]

34. Rogge, N.; Van Reeth, D.; Van Puyenbroeck, T. Performance evaluation of Tour de France cycling teams using data en-velopment analysis. In Proceedings of the XIV IASE \& IV ESEA Conference on Sports Economics, London, UK, 6-7 September 2012.

35. Terrien, M.; Andreff, W. Organisational efficiency of national football leagues in Europe. Eur. Sport Manag. Q. 2019, 20, 205-224. [CrossRef]

36. Herrero-Prieto, L.C. Evaluating the Efficiency of Cultural Travel Destinations: A DEA Approach. In Enhancing Participation in the Arts in the EU; Springer Science and Business Media LLC.: Berlin, Germany, 2017; pp. 237-248.

37. Hofmarcher, M.M.; Paterson, I.; Riedel, M. Measuring Hospital Efficiency in Austria-A DEA Approach. Health Care Manag. Sci. 2002, 5, 7-14. [CrossRef] [PubMed]

38. Glass, A.J.; Kenjegalieva, K.; Taylor, J. Game, set and match: Evaluating the efficiency of male professional tennis players. J. Prod. Anal. 2015, 43, 119-131. [CrossRef]

39. Sitarz, S. The medal points' incenter for rankings in sport. Appl. Math. Lett. 2013, 26, 408-412. [CrossRef]

40. Parshakov, P.; Zavertiaeva, M. Determinants of performance in eSports: A country-level analysis. Int. J. Sport Financ. 2018, 13, 34-51.

41. Júnior, S.G.; De Mello, J.S.; Meza, L.A. Sequential use of ordinal multicriteria methods to obtain a ranking for the 2012 Summer Olympic Games. WSEAS Trans. Syst. 2014, 13, 223-230.

42. Gontijo, T.S. A two-stage DEA model to evaluate the efficiency of countries at the Rio 2016 Olympic Games. Econ. Bull. 2019, 39, 1538-1545.

43. Hsieh, L.-F.; Chin, J.-B.; Wu, M.-C. Cost efficiency and service effectiveness for university e-libraries in Taiwan. Electron. Libr. 2014, 32, 308-321. [CrossRef]

44. Mokhtarian, P.L.; Chen, C. TTB or not TTB, that is the question: A review and analysis of the empirical literature on travel time (and money) budgets. Transp. Res. Part A Policy Pract. 2004, 38, 643-675. [CrossRef]

45. Park, S.; Woo, M.; Nicolau, J.L. Determinant Factors of Tourist Expenses. J. Travel Res. 2020, 59, 267-280. [CrossRef]

46. Voltaire, B.; Galy, O.; Coste, O.; Racinais, S.; Callis, A.; Blonc, S.; Hertogh, C.; Hue, O. Effect of Fourteen Days of Acclimatization on Athletic Performance in Tropical Climate. Can. J. Appl. Physiol. 2002, 27, 551-562. [CrossRef] 
47. Peng, T.L. A Study of the 2004 Athens Olympics Strategic Management. J. Taiwan Soc. Sport Manag. 2015, 15, 193-212. [CrossRef]

48. Knust, S. Scheduling non-professional table-tennis leagues. Eur. J. Oper. Res. 2010, 200, 358-367. [CrossRef]

49. Durán, G.; Durán, S.; Marenco, J.; Mascialino, F.; Rey, P.A. Scheduling Argentina's professional basketball leagues: A variation on the Travelling Tournament Problem. Eur. J. Oper. Res. 2019, 275, 1126-1138. [CrossRef] 